\title{
Crystal Structure Studies and Thermal Characterization of Novel 4-Hydroxychalcone Derivative
}

\author{
SHUBHALAXMI $^{\mathrm{a}}$, STEPHANIE HAHNE ${ }^{\mathrm{a}, \mathrm{b}}$, CARL ZSCHILLE $^{\mathrm{a}, \mathrm{c}}$, \\ A. JAYARAMA ${ }^{\mathrm{d}}$ and K. SUBRAHMANYA BHAT ${ }^{\mathrm{a}^{*}}$
}

${ }^{\text {a } D e p a r t m e n t ~ o f ~ C h e m i s t r y, ~ M a n i p a l ~ I n s t i t u t e ~ o f ~ T e c h n o l o g y, ~ M a n i p a l ~ U n i v e r s i t y, ~}$ Manipal-576104, India

${ }^{\mathrm{b}}$ Technical University Munich, Wissenschaftszentrum Weihenstephan, Freising, Germany

${ }^{c}$ Department of Chemical Process Engineering, Technical University Freiberg, Germany

${ }^{\mathrm{d} D e p a r t m e n t}$ of Physics, Mangalore Institute of Technology \& Engineering (MITE), Moodabidri, 574 225, India

sbkjrf@yahoo.co.in

Received 22 January 2013 / Accepted 16 February 2013

\begin{abstract}
The derivatives of 4-hydroxychalcones were synthesized and characterized by infrared and ${ }^{1} \mathrm{H}$ NMR spectral studies. The grown crystal was further characterized by single crystal x-ray diffraction studies. The crystal structure of (2E)-3-(4-hydroxyphenyl)-1-phenylprop-2-en-1-one was determined using single crystal $\mathrm{x}$-ray diffraction. The compound crystallizes in orthorhombic crystal class in the space group $\mathrm{P} 2{ }_{1} 2_{1} 2_{1}$ with cell parameters $\mathrm{a}=5.3738(4) \AA, \mathrm{b}=12.9239(10) \AA, \mathrm{c}=17.1310(14)$ $\AA, Z=4$ and $V=1189.76 \AA^{3}$. The conjugated compound is slightly twisted with a dihedral angle of $25.00^{\circ}$ between the benzene and hydroxyphenyl ring. Differential scanning calorimetric studies shows that the crystal is stable up to $186{ }^{\circ} \mathrm{C}$.
\end{abstract}

Keywords: Crystal growth, Chalcones, Characterization, Single crystal studies

\section{Introduction}

Phenol-formaldehyde (PF) resin is one among the most widely used synthetic polymer used in day-to-day life due to its good insulating characteristics, easy cure kinetics and cost efficiency $^{1}$. It has been reported that such polymers with wide property variations can be achieved by the simple variation of reaction conditions like $\mathrm{pH}$, catalyst type temperature and the molar ratio of phenolic compound /formaldehyde. Resoles are synthesized under basic conditions with an excess of formaldehyde $(\mathrm{P} / \mathrm{F}$ molar ratio $<1)$ whereas novolacs under acidic conditions and in the presence of excess of phenol ( $\mathrm{P} / \mathrm{F}$ molar ratio $>1)$. They differ in their chemical composition and their properties. Resoles are heat curable and therefore highly crosslinkable. For the synthesis of phenol-formaldehyde resins, the phenol 
has been used widely as it is available in bulk at a cheaper price. By varying the phenolic structure with suitable substituents, it is possible to fine tune the polymer structure with unique properties required for specific applications ${ }^{2-9}$. Chalcones are a class of compounds mostly studied for pharmacological properties ${ }^{10,11}$ and recently have been explored for their optical applications ${ }^{12-15}$. In the past few years chalcones have been shown to possess interesting biological properties like anti-invasive ${ }^{16}$, anticancer ${ }^{17,18}$, antimalarial ${ }^{19}$, antimicrobial $^{20}$, antimutagenic ${ }^{21}$, radioprotective ${ }^{22}$, anti-inflammatory effects ${ }^{23}$ and find use as synthetic intermediates ${ }^{24}$.

Recently we explored hydroxyphenyl compounds for their application as monomer in the synthesis of resole/novolacs type resins. The objective of the present work is to synthesize the chalcone derivative having a hydroxyl function (Scheme 1), growth of single crystals using slow evaporation technique and its characterization by IR, ${ }^{1} \mathrm{H}$ NMR, DSC and single crystal studies.

\section{Experimental}

The chemicals and solvents required in the synthesis were obtained from commercial sources and were used without further purification. Melting point of the compound was determined using open capillary method and is uncorrected. Thin layer chromatography was carried out using silica gel plates and ethyl acetate: hexane (1:9) solvent system. Infrared spectra were recorded using SHIMADZU- 8400S FT-IR spectrometer in the wavenumber range $400-4000 \mathrm{~cm}^{-1}$ by $\mathrm{KBr}$ pellet technique. ${ }^{1} \mathrm{H}$ NMR spectra was recorded using Bruker 400MHZ NMR spectrometer using $\mathrm{CDCl}_{3}$ as solvent.

\section{Synthesis of 4-hydroxychalcone}

The required chalcone (3) was prepared by reacting 4-hydroxybenzalaldehyde (1) (10 mmole) and acetophenone (2) $(10 \mathrm{mmole})$ in a $250 \mathrm{~mL}$ round bottom flask using ethanol as solvent. The reaction was carried out at room temperature and with gradual addition of $\mathrm{NaOH}$ solution (Scheme 1). The progress of the reaction was monitored using thin layer chromatography. After continuous stirring for $6 \mathrm{~h}$, the reaction was completed. The solution was then acidified using $\mathrm{HCl}(4 \mathrm{~N})$ till a $\mathrm{pH}$ of 3 is reached. The product was collected by vacuum filtration and was further purified by crystallization from ethanol. A yellow, powdery product with a melting point of $180-186^{\circ} \mathrm{C}(60 \%)$ was obtained ${ }^{25}$.<smiles>O=Cc1ccc(O)cc1</smiles>

(1)<smiles>CC(=O)c1ccccc1</smiles>

(2)

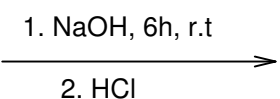

2. $\mathrm{HCl}$

Scheme 1. Synthesis of hydroxychalcone (3)

\section{Characterization}

\section{Fourier transform infrared (FT-IR) and ${ }^{1} H$ NMR studies}

The IR spectrum of hydroxychalcone (3) shows characteristic wavenumber at $1651 \mathrm{~cm}^{-1}$ attributable to the $\mathrm{C}=\mathrm{O}$ stretch of $\alpha, \beta$-unsaturated ketone, confirming the formation of chalcone. A broad band observed at $3350 \mathrm{~cm}^{-1}$ corresponds to the presence of phenolic group. 
The ${ }^{1} \mathrm{H}$ NMR spectra of 4-hydroxychalcone recorded using $\mathrm{CDCl}_{3}$ as solvent and the spectra is in agreement with the structure of the title compound. Proton NMR spectrum of the compound showed a broad singlet at $\delta 5.72$ integrating for one proton is due the presence of phenolic $\mathrm{OH}$ group. Other characteristic protons appeared in the range $\delta$ 6.9-8.0 integrating for eleven protons is attributable to aromatic and $-\mathrm{CH}=\mathrm{CH}-$ protons.

\section{Differential scanning calorimetry studies}

The thermal property of the synthesised compound was studied in the powder form by recording the differential scanning colorimeter (DSC) response curve in the temperature range $30{ }^{\circ} \mathrm{C}$ to $200{ }^{\circ} \mathrm{C}$, at a heating rate of $10{ }^{\circ} \mathrm{C} / \mathrm{min}$, in nitrogen atmosphere using SHIMADZU differential scanning calorimeter (DSC-60). The DSC plot in Figure 1 shows an endothermic peak at $186{ }^{\circ} \mathrm{C}$, which corresponds to the melting point of the compound. Further it indicates that there are no other phase transitions before melting. The sharpness of the peak shows the good degree of crystallinity and purity of the sample.

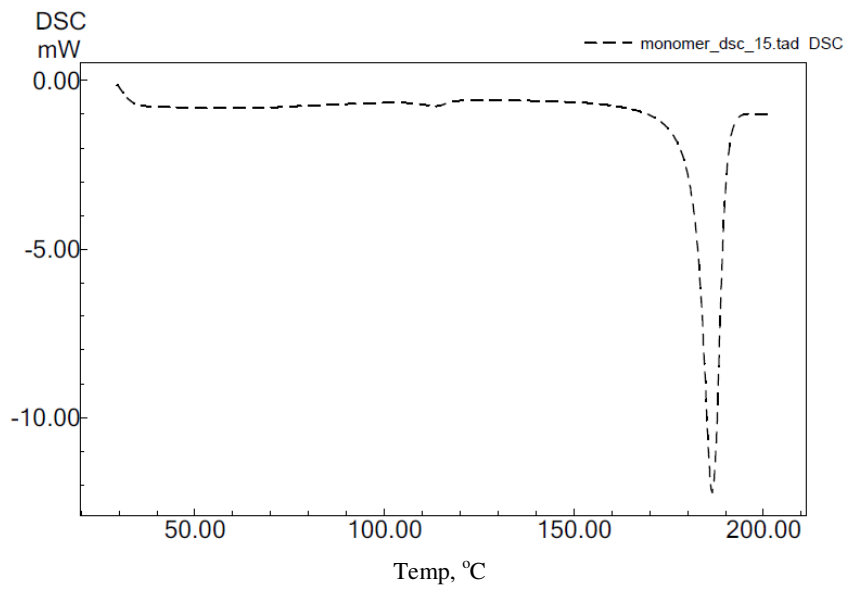

Figure 1. DSC curve for 4-hydroxychalcone

\section{Single crystal growth and structural studies}

The solubility studies in different solvents showed the compound is insoluble in water, highly soluble in $N, N$-dimethylformamide (DMF) and as moderately soluble ethyl acetate. To grow single crystals of 4-hydroxychalcone, ethyl acetate was used as solvent. A known volume of solvent was taken in a conical flask, which was kept under heat in a constant temperature bath. The finely powdered sample was added until the dissolution ceased. Then the solution was kept for slow evaporation at room temperature for $72 \mathrm{~h}$. The needle type crystals initially formed after $48 \mathrm{~h}$ were kept further $24 \mathrm{~h}$ to form sufficiently bigger size crystals.

A good quality single crystal of dimension $0.35 \times 0.25 \times 0.2 \mathrm{~mm}$ is used for data collection using a Bruker kappa Apex II diffractometer. The data was collected at room temperature using Mo K alpha radiation at a generator setting of $50 \mathrm{KV}$ and $30 \mathrm{~mA}$. Cell refinement was done using APEX2/SAINT. Data reduction was done using SAINT/ XPREP. Multi-scan absorption correction method was followed with reference to SADABS. The structure was solved by SIR92 in Wingx suit ${ }^{26}$ and refinements were done with SHELXL-97 in the WinGx package suite (Version 1.80 .05$)^{27}$. The crystallographic details are provided in Table 1. 
Table 1. Crystal data and structure refinement for 4-hydroxychalcone [CCDC deposition No. 905180]

\begin{tabular}{ll}
\hline \multicolumn{1}{c}{ Identification code } & \multicolumn{1}{c}{ shelxl } \\
\hline Empirical formula & $\mathrm{C}_{15} \mathrm{H}_{12} \mathrm{O}_{2}$ \\
Formula weight & 224.25 \\
Temperature & $296(2) \mathrm{K}$ \\
Wavelength & $0.71073 \mathrm{~A}$ \\
Crystal system, space group & Orthorhombic, $\mathrm{P} 2{ }_{1} 2_{1} 2_{1}$ \\
Unit cell dimensions & $\mathrm{a}=5.3738(4) \mathrm{A}, \mathrm{b}=12.9239(10) \mathrm{A}, \mathrm{c}=17.1310(14) \mathrm{A}$ \\
Volume & $1189.76(16) \mathrm{A}^{3}$ \\
Z, Calculated density & $4,1.252 \mathrm{mg} / \mathrm{m}^{3}$ \\
Theta range for data collection & 1.97 to $28.22 \mathrm{deg}$. \\
Reflections collected / unique & $8401 / 2908$ R(int) $=0.0204]$ \\
Completeness to theta $=28.22$ & $99.1 \%$ \\
Absorption correction & semi-empirical from equivalents \\
Max. and min. transmission & 0.9837 and 0.9757 \\
Refinement method & Full-matrix least-squares on $\mathrm{F}^{2}$ \\
Goodness-of-fit on $\mathrm{F}^{\wedge} 2$ & 1.054 \\
Final R indices [I $>2$ sigma(I)] & $\mathrm{R} 1=0.0407, \mathrm{wR} 2=0.0928$ \\
R indices (all data) & $\mathrm{R} 1=0.0769, \mathrm{wR} 2=0.1105$ \\
\hline
\end{tabular}

The synthesised compound exists as the most stable $(E)$-configuration, crystallizes orthorhombic system, $\mathrm{P} 2_{1} 2_{1} 2_{1}$ space group with $\mathrm{Z}=4$. The molecular structure of 4-hydroxy chalcone with thermal ellipsoid drawn at $50 \%$ probability level is shown in Figure 2. The non-centrosymmetric crystal packing of 4-hydroxychalcone is consolidated by two weak $\mathrm{C}-\mathrm{H} \cdots \mathrm{O}$ intermolecular hydrogen bond interactions and the corresponding geometric parameters are tabulated in Table 2. Packing of the molecules when viewed along the axis a is shown in Figure 3. Anisotropic displacement parameters, hydrogen coordinates and isotropic displacement parameters can be obtained free of cost by referring to CCDC No 905180. It is interesting to note that the dihedral angle between benzene ring and hydroxyphenyl ring is $25.00^{\circ}$, which indicates the non-planar geometry of the crystal structure. The hydroxyphenyl ring is connected to the phenyl group through the $\mathrm{C} 6-\mathrm{C} 7=\mathrm{C} 8$ C9-C10 chain with the $\mathrm{C}=\mathrm{C}$ bond length being 1.330 (3) $\AA$. The analysis of weak intermolecular interactions reveals that crystalline lattice is held together by weak intermolecular $\mathrm{C}-\mathrm{H} \cdots \mathrm{O}$ hydrogen bond. The mean plane of phenyl ring $(\mathrm{C} 10-\mathrm{C} 15)$ is deviated from a plane (O2-C9-C10) by an angle of $9.95^{\circ}$. In the same way the mean plane of hydroxy phenyl ring (C1-C6) is deviated from a plane (H1O1-O1-C3) by an angle of $17.27^{\circ}$. The crystal structure is further stabilized by very weak aromatic stacking interactions.

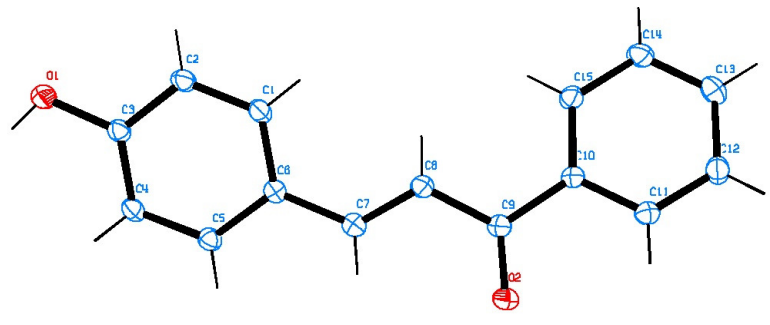

Figure 2. ORTEP diagram of 4-hydroxychalcone, thermal ellipsoids were drawn at 50\% probability level 
Table 2. Geometries of intermolecular Interactions obtained from structural analysis of 4-hydroxychalcone

\begin{tabular}{cccccc}
\hline Interactions & $\mathrm{X}-\mathrm{H}(\AA)$ & $\begin{array}{c}\mathrm{H} \cdots \mathrm{D} \\
(\AA)\end{array}$ & $\mathrm{X} \cdots \mathrm{D}(\AA)$ & $\begin{array}{c}\mathrm{X}-\mathrm{H} \cdots \mathrm{D} \\
\left({ }^{\circ}\right)\end{array}$ & Symmetry \\
\hline $\mathrm{C} 15-\mathrm{H} 15 \ldots \mathrm{O} 1$ & $0.931(2)$ & 2.601 & $3.456(2)$ & $153.1(1)$ & $-1 / 2+\mathrm{x}, 1 / 2-\mathrm{y}, 1-\mathrm{z}$ \\
$\mathrm{C} 1-\mathrm{H} 1 \ldots \mathrm{C} 2$ & $0.930(2)$ & 2.859 & $3.701(3)$ & $151.1(1)$ & $-1 / 2+\mathrm{x}, 1 / 2-\mathrm{y}, 1-\mathrm{z}$ \\
$\mathrm{C} 9-\mathrm{O} 2 \ldots \mathrm{H} 4$ & $1.228(2)$ & 2.713 & $3.812(2)$ & $148.2(1)$ & $1.5-\mathrm{x},-\mathrm{y}, 1 / 2+\mathrm{z}$ \\
$\mathrm{C} 9-\mathrm{O} 2 \ldots \mathrm{O} 1$ & $1.228(2)$ & 2.682 & $3.796(2)$ & $150.1(1)$ & $1.5-\mathrm{x},-\mathrm{y}, 1 / 2+\mathrm{z}$ \\
$\mathrm{C} 9-\mathrm{O} 2 \ldots \mathrm{H} 1 \mathrm{O} 1$ & $1.228(2)$ & 1.87 & $2.988(2)$ & $148.7(1)$ & $1.5-\mathrm{x},-\mathrm{y}, 1 / 2+\mathrm{z}$ \\
\hline
\end{tabular}

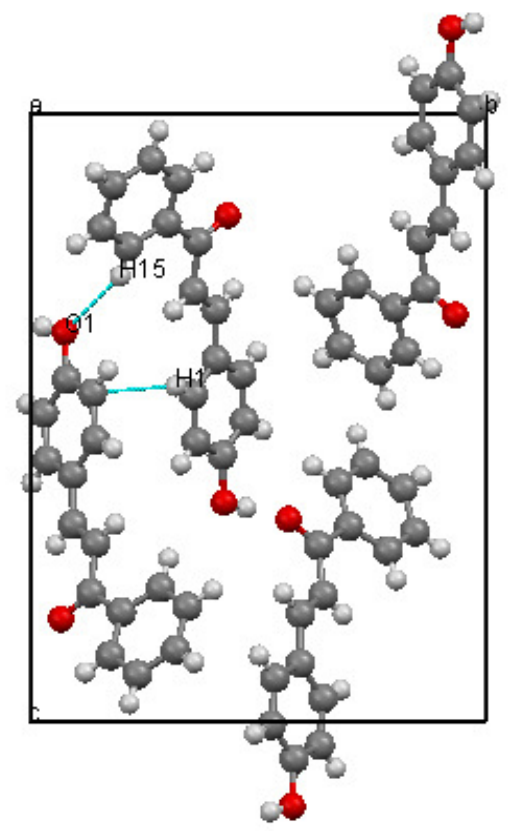

Figure 3. Packing of the molecules when viewed down the a axis

\section{Conclusion}

A novel 4-hydroxychalcone is synthesized and crystals of this compound were successfully grown by the solution growth technique. The functional groups present in the synthesized crystal were identified using FTIR and ${ }^{1} \mathrm{H}$ NMR spectrum. Single crystal XRD studies indicate the non-centrosymmetric structure of the crystal. The crystal has high melting point indicating potential applications in device fabrication. There is ample scope for further study on optical properties and also this is a potential molecule to be explored as monomer in the synthesis of resole type resins.

\section{Acknowledgment}

Stephanie Hahne and Carl Zschille are thankful to IAESTE for providing an internship at MIT, Manipal. Shubhalaxmi is thankful to Manipal University for fellowship under MUstructured $\mathrm{PhD}$ programme. We are also thankful to Prof A. Vittaleshwar, Associate Director-Planning and Prof Vinod V Thomas, Director, MIT, Manipal for providing necessary financial support. We appreciate Dr. Shibu Eappan, SAIF, Kochi for timely help in getting single crystal XRD data. 


\section{References}

1. Poljansek I and Krajnc M, Acta Chim Slov., 2005, 52(3), 238-244.

2. Schwaner C, J Poly Sci., 1958, 31(122), 177-179.

3. Wang C S and Lee M C, J Appl Poly Sci., 1998, 70(10), 1907-1921.

4. McRae C, Fuel and Energy Abstr (Elsevier), 1998, 39(3), 169.

5. Kim MG, Amos L W and Edwin E B, J Poly Sci Part A: Poly Chem., 1993, 31(7), 1871-1877.

6. Mandal H and Hay A S, J Poly Sci Part A: Poly Chem., 1998, 36(11), 1911-1918.

7. Enikolopyan N S, Markevitch M A, Sakhonenko L S, Rogovina S Z and Oshmyan V G, $J$ Poly Sci Part A: Poly Chem., 1982, 20(5), 1231-1245.

8. Lee KY, Kim DJ, Kim H J, Hwang T S, Rafailovich M and Sokolov J, J Appl Poly Sci., 2003, 89(10), 2589.

9. Markovic S, Dunjic B, Zlatanic A and Djonalgic J, J Appl Poly Sci., 2001, 81, 1902.

10. Novokovska Z, Eur J Med Chem., 2007, 42(2), 125-137.

11. Doan T N and Tran D T, Pharmacol Pharm., 2011, 2, 282-288.

12. Crasta V, Ravindrachary V, Lakshmi S, Pramod S N, Shridar M A and Shashidhara P J, J Cryst Growth, 2005, 275, e329.

13. Prabhu A N, Jayarama A, Bhat K S and Upadhyaya V, J Mol Str., 2013, 1031, 79-84.

14. Prabhu A N, Jayarama A, Upadhyaya V and Bhat K S, Mat Chem Phy., 2013, 138, 179-185.

15. Shubhalaxmi, Hahne S, Jayarama A and Bhat K S, Chem Sci Trans., 2013, DOI: $10.7598 /$ cst2013.438.

16. Mukherjee S, Kumar V, Prasad A K, Raj H G, Bracke M E, Olsen C E, Jain S C and Parmar V S, Bioorg Med Chem., 2001, 9(2), 337-345.

17. Lawrence N J, McGown, A T, Ducki S and Hadfield J A, Anti-Cancer Drug Des., 2000, 15(2), 135-141.

18. Bois F, Boumendjel A, Mariotte A M, Conseil G and Di P A, Bioorg Med Chem., 1999, 7(12), 2691-2695.

19. Ran VJ, Saxena A S, Srivastava S and Chandra S, Bioorg Med Chem Lett., 2000, 10(19), 2159-2161.

20. Kidwai M, Sapra P, Misra P, Saxena R K and Sing M, Bioorg Med Chem., 2001, 9(2), 217-220.

21. Edenharder R, Ranscher R and Platt K L, Mutat Res., 1997, 379, 21.

22. Blickenstaff R T, Hanson W R, Reddy S and Witt R, Bioorg Med Chem., 1995, 3(7), 917-922.

23. Hsieh H K, Tsao L T, Wang J P and Lin C N, J Pharm Pharmacol., 2000, 52(2), 163-171.

24. Choudary B M, Lakshmi K M, Venkat R C R, Koteswara R K and Figueras F, J Mol Catal A, 1999, 146(1-2), 279-284.

25. Kumar N, Jain J S, Sinha R, Garg V K and Bansal S K, Der Pharm Lett., 2009, 1(1), 169-176.

26. Sheldrick G M, Acta Cryst., 2008, A64, 112-122.

27. Farrugia L J, J Appl Cryst., 1999, 32, 837-838. 